INTERNATIONAL JOURNAL OF MULTIDISCIPLINARY RESEARCH AND ANALYSis

ISSN(print): 2643-9840, ISSN(online): 2643-9875

Volume 04 Issue 05 May 2021

DOI: 10.47191/ijmra/v4-i5-10, Impact Factor: 6.072

Page No.- 561-571

\title{
Phenotypic Performance and Response to Selection for Body Weight Traits of Black Bengal Goat (BBG) in a Community Breeding Program
}

\author{
A. Akhtar ${ }^{1}$, M.A. Hoque ${ }^{2}$, A.K.F.H. Bhuiyan ${ }^{3}$, M.R. Amin ${ }^{4}$, M.A. Habib \\ ${ }^{1}$ Department of Livestock Services (DLS), Farmgate, Dhaka, Bangladesh. \\ 2,3,4 Department of Animal Breeding and Genetics, Bangladesh Agricultural University (BAU), Mymensingh \\ ${ }^{5}$ Bangladesh Livestock Research Institute (BLRI), Savar, Dhaka, Bangladesh.
}

\begin{abstract}
This piece of work was conducted to investigate the genetic improvement of body weight (BW) in Black Bengal goat (BBG) in-situ through a community based breeding program under a low input production system. Data on a total of 466 individuals from three villages; Gangatia, Borochala and Pachpai at Bhaluka upazila in Mymensingh district from 2009 to 2015 with three progressive generations were taken for this work. Two breeding strategies (BS); mating among selected superior bucks and does (denoted as $\mathrm{BS}_{1}$ ) and mating existing does with selected superior bucks (denoted as $\mathrm{BS}_{2}$ ) were followed for mating plan of the community breeding program. A control or test group with mating among existing bucks and does (denoted as BS 3 ) were also observed to compare with treatment groups. Phenotypic performance and genetic parameters for BW traits were studied. Data were analyzed by SPSS 17.0 and VCE 4.2.5. The average BW at birth, 3-month, 6-month, sexual maturity, 9-month, and 12-month were $1.42 \pm 0.03,5.14 \pm 0.07,8.48 \pm 0.17,9.88 \pm 0.16,11.75 \pm 0.16$ and $15.19 \pm 0.16 \mathrm{~kg}$, respectively, having significant effect for sex $(p<0.05-p<0.001)$, generation $(p<0.001)$ and BS $(p<0.001)$. The heritability estimates for $B W$ traits were medium ranging from 0.45 to 0.57 . The genetic correlation $\left(r_{g}\right)$ and phenotypic correlation $\left(r_{p}\right)$ for BW traits were positive with low to high strengths $(0.02$ to 0.99 for $r_{g}$ and $0.17^{* *}$ to $0.99 * *$ for $r_{p}$ ). The average realized responses due to selection in three progressive generations for BW traits varied from 0.123 to $0.480 \mathrm{~kg}$ per generation. It may be concluded that community based breeding program with selected superior bucks and does is very rationale under low input production system, as it improved BW in progressive generations. However, estimates of heritability and $r_{g}$ indicated further scope of improvement by continuous culling of inferior does and bucks in breeding program.
\end{abstract}

KEYWORDS: Black Bengal goat, community breeding, body weight, genetic parameter, response to selection.

\section{INTRODUCTION}

Goat is one of the potential small ruminants for the rural people of Bangladesh. However, goats are said to be "poor man's cow" as they are living resort for resource of poor rural people (MacHugh and Bradley, 2001). About 83\% of total goats in Bangladesh are reared by small, marginal and landless farmers, $15 \%$ by medium, $2 \%$ by large farmers with almost zero input (BBS, 2010) and their mean flock size ranges from 2-5 (Amin, 2006). Owing to small size, goats can easily be handled and managed by women and children (Acharya and Bhattacharya, 1992). Goat also displays a unique ability to adapt and maintain themselves in harsh environments, having short generation intervals with a higher rate of prolificacy, lower feed and capital requirements (Iniguez, 2004) with less space. Therefore, goat keeping has become a subsidiary source of income to smallholders as well as landless peasants in the rural community.

Among other types of available goats, Black Bengal goats (BBG) are heritage and pride of Bangladesh due to their delicious meat, prolificacy and adaptability in terms of disease resistance and reproducibility to harsh environments. Despite having numbers of superior virtues, BBG also have some limitations too. They are inferior in some economic traits such as birth weight, growth rates, milk yield, and kid survivability (Amin et al., 2001; Chowdhury et al., 2002; Rokonuzzaman, 2000). Dam's poor milk yield even some times which are not sufficient to feed their kids has also been identified as determinant of slow pre-weaning growth and higher kid mortality (Husain, 1993). However, another limitation is not directly due to genetics of BBG, but rather than the system of breeding, often the poorest males are used for breeding, leading to negative selection response (Amin, 2014). 


\section{Phenotypic Performance and Response to Selection for Body Weight Traits of Black Bengal Goat (BBG) in a Community Breeding Program}

Poor productions of both milk and meat of BBGs are due to their poor genetic makeup, improper nutrition and management. The interaction of genetics and nutrition is important and nutrition does not increase the production beyond the genetic potentialities (Islam et al., 2009). But research shows that there exists substantial genetic variations among individuals in the production traits of BBG, indicating scope for increasing productivity through breeding approaches (Amin, 2014). Husain (1993) also argued that BBG is a high potential for its further improvement through selective breeding as there exists large within breed variations and there are individuals with outstanding performance even under field condition. But due to small body size, meat produced by this type of goat does not make a high economic return. As BBGs are being reared primarily for meat production, BW and growth rate could be considered as the most important factors.

\section{MATERIALS AND METHODS \\ Location of the study}

The study was conducted at a rural community level goat flocks of three different villages; Gangatia, Borochala and Pachpai at Bhaluka upazila (sub-district) in Mymensingh district of Bangladesh. Bhaluka is geographically located in between $24^{\circ} 16^{\prime}$ and $24^{\circ} 29^{\prime} \mathrm{N}$ latitude and in between $90^{\circ} 14^{\prime}$ and $90^{\circ} 29^{\prime} \mathrm{E}$ longitudes. The study area is located at $70 \mathrm{~km}$ north from the capital city, Dhaka.

\section{Ecology and climate}

The ecology of three villages of Bhaluka is more or less similar having temperature ranges from $12^{\circ} \mathrm{C}$ (winter) to $33^{\circ} \mathrm{C}$ (summer), and the annual rainfall averages $2147 \mathrm{~mm}$ during the study period. High lands were available which were reddish in color, some forests present in Pachpai village. Grazing lands were available in Gangatia, Borochala and Pachpai village for the goat.

\section{Selection of parents}

Superior bucks and does were selected to establish foundation flocks in three village communities. The superior bucks were selected from Bangladesh Livestock Research Institute (BLRI), Department of livestock Services (DLS) and also from the existing village flocks based on physical appearance and BW, taking history from the goat owners. During selection of bucks, BW at 6month $\geq 8 \mathrm{~kg}$, good body conformation, dams yielded at least $250 \mathrm{ml}$ milk/day and kidded $\geq 2$ kids in previous birth(s) were taken into consideration. Superior does were selected on the basis of adult body weight (preferably $>15.0 \mathrm{~kg}$ ), litter size (preferably multiple, $\geq 2$ kids per kidding), daughter of a prolific dam who yielded at least $250 \mathrm{ml}$ milk/day and kidded $\geq 2$ kids in previous birth(s) and free from any kind of defects and diseases.

\section{Husbandry practices}

Traditional housing with semi-intensive management system was practiced by the BBG keeper farmers. The bucks and does were allowed to graze separately tethered by rope in naturally available pasture land and adjoining fields of the farmer's house. Goats were also provided with tree leaves, kitchen waste, leftover of family meals, table salt and cut and carry green grass ad lib during the day time. Goats were allowed to feed concentrate feed such as rice gruel, rice bran, broken rice, wheat bran etc. during pregnancy and lactation period @ $200 \mathrm{~g} /$ day. The breeding bucks were also fed whole gram @ $50 \mathrm{~g} /$ day in the morning. Fresh drinking water was also supplied for the goat ad lib. All goats under the project areas were vaccinated and de-wormed routinely against prevalent diseases and parasites.

\section{Breeding and selection}

For mating does with superior bucks, three "Buck Parks" in each village were established by the foreign aided project. Superior bucks were kept in the buck park most of the time except feeding and exercise for half an hour twice in a day. Two breeding strategy (BS) or interventions were followed as; mating among selected superior bucks and does (those supplied to the farmers by the project aid) denoted as $\mathrm{BS}_{1}$, mating of existing does (owned by the community farmers) with selected superior bucks denoted as $\mathrm{BS}_{2}$. A control or test group with mating among existing does and bucks, denoted as $\mathrm{BS}_{3}$ was also observed to compare with other two intervention groups. Only superior males based on their BW were selected as sire to produce progeny in progressive generations.

\section{Recording data}

All animals were neck tagged and data sheet for each individual were maintained for recording data. The data was collected over 3 progressive generations from three flocks. There were a total of 657 individuals ( 101 males and 556 females) consisting 285 base populations ( 25 males and 260 females) and 372 progeny ( 76 males and 296 females) from three flocks in three progressive generations included in this study. 


\section{Phenotypic Performance and Response to Selection for Body Weight Traits of Black Bengal Goat (BBG) in a Community Breeding Program}

\section{Statistical model and data analysis}

The study covered various economic BW traits of BBG in progressive generations. The animals were of different populations and ages as well as both parents and progeny groups. Therefore, data were sufficient un-balanceness and hierarchy in nature. So, statistical design of the study was essentially non-orthogonal factorial in nature. Descriptive statistics, analysis of variance and phenotypic correlations (Pearson's model) were performed using SPSS 17.0 (1998) software. The significance of independent variables (fixed or non-genetic factors) was tested by least-squares analyses of variance using the general linear model (GLM) procedure as given below:

$$
Y_{i j k l m}=\mu+S_{i}+G_{j}+B_{k}+F_{l}+e_{i j k l m}
$$

where, $Y_{\mathrm{ijklm}}=$ Record of $\mathrm{m}^{\text {th }}$ kid belonging to $\mathrm{i}^{\text {th }}$ sex, born in $\mathrm{j}^{\text {th }}$ generation under $\mathrm{k}^{\text {th }}$ breeding strategy in $\mathrm{I}^{\text {th }}$ village flock.

$\mu=$ Overall population mean for BW traits;

$\mathrm{S}_{\mathrm{i}}=$ Effect of $\mathrm{i}^{\text {th }}$ sex (where $\mathrm{i}=$ male and female),

$\mathrm{G}_{\mathrm{j}}=$ Effect of $\mathrm{j}^{\text {th }}$ generation (where $\mathrm{j}=1^{\text {st }}$ generation, $2^{\text {nd }}$ generation and $3^{\text {rd }}$ generation),

$\mathrm{B}_{\mathrm{k}}=$ Effect of $\mathrm{k}^{\text {th }}$ breeding strategy (where $\mathrm{k}=\mathrm{BS}_{1}, \mathrm{BS}_{2}$ and $\mathrm{BS}_{3}$ ),

$\mathrm{F}_{\mathrm{l}}=$ Effect of $\mathrm{I}^{\text {th }}$ flock (where I = Gangatia, Borochala and Pachpai),

$\mathrm{e}_{\mathrm{ijk} \mathrm{j} m}=$ Random residual error associated with $\mathrm{Y}_{\mathrm{ijkl}}$ observation

\section{Estimation of genetic parameters}

The genetic parameters including (co)variance components, heritability and genetic correlations were estimated by using VCE 4.2.5 (Groeneveld, 1998) package with residual maximum likelihood (REML) approach. For REML analysis, animal model was used considering sex, generation, BS and flock as fixed effects. The general form of the animal model was as follows:

\section{$\boldsymbol{Y}=\mathrm{Xb}+\mathrm{Za}+\boldsymbol{W c}+\boldsymbol{e}$}

where,

$Y=$ Vector of observations

$\mathrm{X}, \mathrm{Z}$, and $\mathrm{W}=$ Known incidence matrices associated with levels of $\mathrm{b}$, $\mathrm{a}$ and $\mathrm{c}$ with $\mathrm{Y}$.

$b=$ Unknown vector of fixed effects (i.e. sex, generation, BS and flock)

$\mathrm{a}=$ Unknown vector of breeding value

$c=$ Unknown vector of permanent environmental effects

$\mathrm{e}=$ Vector of residual effect

\section{Estimation of response to selection}

The predicted or expected responses to selection in the progressive generations for the economic important traits were estimated using the following formula given by Falconer (1989):

\section{$R=i \times s d_{p} \times h^{2}$}

where, $R=$ response to selection in the next generation for the trait;

$\mathrm{i}=$ selection intensity;

$h^{2}=$ heritability of the trait;

$s d_{p}=$ phenotypic standard deviation of the trait.

The observed or actual response to selection was the difference of phenotypic mean between progeny of the selected parents and group of the selected parents.

\section{RESULTS AND DISCUSSION}

\section{Body weight at different ages}

The least squares means for BW at different ages in Black Bengal goat (BBG) as affected by sex, generation, breeding strategy (BS) and flock are illustrated in Table 1. Irrespective of sex, generation, BS and flock, the overall mean body weight (BW) at birth (BW0), 3-month (BW3), 6-month (BW6), sexual maturity (BWSM), 9-month (BW9) and 12-month (BW12) ages are 1.42 $\pm 0.03,5.14 \pm 0.07$, $8.48 \pm 0.17,9.88 \pm 0.16,11.75 \pm 0.16$ and $15.19 \pm 0.16 \mathrm{~kg}$, respectively. Earlier, Majumder (2011) and Faruque et al. (2010) reported BW0 to be $1.3 \pm 0.02$ and $1.28 \pm 0.11 \mathrm{~kg}$ for the same breed which agreed with our result. However, Haque (2014), Paul et al. (2011), Mia (2011) documented somewhat lower BWO ranged from 0.98 to $1.20 \mathrm{~kg}$. Mia (2011) and Paul et al. (2011) as obtained BW3 to be 5.12 and $5.22 \pm 0.33 \mathrm{~kg}$ in their studies which are in the line of our study. Somewhat lower BW3 of $4.67 \pm 0.15$ and $4.88 \pm 0.22 \mathrm{~kg}$ were also investigated by Islam (2014) and Haque (2014). Rahman (2007) and Haque (2014) found BW6 as to be 7.68 and $8.02 \pm 0.31$ $\mathrm{kg}$, respectively which are somewhat lower than our study. Faruque et al. (2010) obtained BWSM in BBG to be $9.62 \pm 0.76$ and $9.34 \pm 0.62 \mathrm{~kg}$ for intensive and semi-intensive management system respectively. Ray et al. (2016) reported $9.47 \pm 0.53 \mathrm{~kg} B W$ at 


\section{Phenotypic Performance and Response to Selection for Body Weight Traits of Black Bengal Goat (BBG) in a Community Breeding Program}

puberty for indigenous goat in northern Odisha which corroborates with this study. Haque (2014) and Mia (2011) in their studies obtained somewhat lower estimates of BW9 $(10.56 \pm 0.41$ and $10.92 \pm 2.72 \mathrm{~kg})$ than our estimate. But, Paul et al. (2011) reported $12.05 \pm 0.47 \mathrm{~kg}$ BW9 in male BBG, which is slightly higher than our study. Haque (2014) and Mia (2011) in their same flock reported BW12 as $14.48 \pm 0.24$ and $14.47 \pm 3.55 \mathrm{~kg}$, respectively which are concomitant with this study. But, Paul et al. (2011) obtained BW12 to be $14.20 \pm 0.20$ and $12.40 \pm 0.41 \mathrm{~kg}$ for bucks and does which are likely lower to some extent as compare to our study. The variations of BW at different ages for the same genotype among researchers could be due to difference of population, sample size, feeding and management system or methods of analysis.

Sex significantly influenced live BW for all ages, and in all cases males were heavier than those of females. Earlier, Amin et al. (2001), Husain (1999), Mia (2011), Haque (2014), Paul et al. (2011) and Alam (2006) observed the same effect of sex on BW. Conversely, Haque (2014) and Mia (2011) found no significant differences for BW0 and BW3 between sexes. Actually, heavier weight in males compared to females is common phenomenon usually happened for most species of animals. This is due to genetic architecture of male and female controlled by specific genes.

Generation had highly significant $(p<0.001)$ effect on BW at all ages with the trend of increasing gradually in later generations which is in general agreement with Haque (2014), Akhter et al. (2006) and Amin et al. (2001). This could be due to selection of superior parents in progressive generations.

Breeding strategy (BS) had significant role of variability BW in progressive generations. The progeny produced from $\mathrm{BS}_{1}$ had significantly $(p<0.001)$ higher $\mathrm{BW}$ at all ages than those progeny produced from $\mathrm{BS}_{2}$ and $\mathrm{BS}_{3}$. This was due to higher genetic potentiality of the parents that transmitted to their offspring. The published literatures regarding the effect of BS was not available to compare with our study, because community based breeding program giving intervention on selection and breeding among superior bucks and does was very rarely conducted earlier.

Flock had no significant ( $p>0.05$ ) effect on BW at all ages. In general agreement, Islam (2014) did not find any variations of BW at 3 and 6-month of ages in BBG among different locations where the author worked. Conversely, Haque (2014) found significant variations of $B W$ at 3, 6, 9 and 12-month of ages among three populations. Actually, variations for feeding and management in different populations could be the reason for differences of BW in the same genotype.

Table 1: Body weight of Black Bengal goat at different ages

\begin{tabular}{|c|c|c|c|c|c|c|}
\hline \multirow{2}{*}{ Factor } & \multicolumn{6}{|c|}{ Body weight (Mean \pm SE) } \\
\hline & BWO & BW3 & BW6 & BWSM & BW9 & BW12 \\
\hline Sex & $* * *$ & $*$ & $* * *$ & $* * *$ & $* *$ & $* * *$ \\
\hline Male & $\begin{array}{l}1.66 \pm 0.03 \\
(101)\end{array}$ & $\begin{array}{l}5.60 \pm 0.12 \\
(099)\end{array}$ & $\begin{array}{l}9.22 \pm 0.27 \\
(099)\end{array}$ & $\begin{array}{l}10.34 \pm 0.25 \\
(073)\end{array}$ & $\begin{array}{l}12.76 \pm 0.25 \\
(099)\end{array}$ & $\begin{array}{l}16.62 \pm 0.26 \\
(099)\end{array}$ \\
\hline Female & $\begin{array}{l}1.17 \pm 0.02 \\
(365)\end{array}$ & $\begin{array}{l}5.01 \pm 0.08 \\
(352)\end{array}$ & $\begin{array}{l}7.74 \pm 0.14 \\
(352)\end{array}$ & $\begin{array}{l}09.41 \pm 0.12 \\
(296)\end{array}$ & $\begin{array}{l}10.74 \pm 0.13 \\
(352)\end{array}$ & $\begin{array}{l}13.76 \pm 0.13 \\
(352)\end{array}$ \\
\hline Generation & $* * *$ & $* * *$ & $* * *$ & $* * *$ & $* * *$ & $* * *$ \\
\hline $\mathrm{G}_{0}$ & $\begin{array}{l}1.30^{c} \pm 0.03 \\
(156)\end{array}$ & $\begin{array}{l}4.94^{c} \pm 0.13 \\
(155)\end{array}$ & $\begin{array}{l}7.76^{c} \pm 0.18 \\
(155)\end{array}$ & $\begin{array}{l}09.30^{c} \pm 0.16 \\
(135)\end{array}$ & $\begin{array}{l}10.72^{\mathrm{C}} \pm 0.17 \\
(155)\end{array}$ & $\begin{array}{l}13.68^{c} \pm 0.17 \\
(155)\end{array}$ \\
\hline $\mathrm{G}_{1}$ & $\begin{array}{l}1.38^{\mathrm{c}} \pm 0.03 \\
(203)\end{array}$ & $\begin{array}{l}4.90^{c} \pm 0.10 \\
(191)\end{array}$ & $\begin{array}{l}8.09^{c} \pm 0.17 \\
(191)\end{array}$ & $\begin{array}{l}09.66^{\mathrm{c}} \pm 0.14 \\
(160)\end{array}$ & $\begin{array}{l}11.28^{\mathrm{C}} \pm 0.15 \\
(191)\end{array}$ & $\begin{array}{l}14.45^{\mathrm{c}} \pm 0.15 \\
(191)\end{array}$ \\
\hline $\mathrm{G}_{2}$ & $\begin{array}{l}1.43^{\mathrm{b}} \pm 0.04 \\
(068)\end{array}$ & $\begin{array}{l}5.54^{b} \pm 0.17 \\
(066)\end{array}$ & $\begin{array}{l}8.76^{b} \pm 0.27 \\
(066)\end{array}$ & $\begin{array}{l}10.18^{b} \pm 0.22 \\
(050)\end{array}$ & $\begin{array}{l}12.18^{\mathrm{b}} \pm 0.24 \\
(066)\end{array}$ & $\begin{array}{l}15.74^{b} \pm 0.25 \\
(066)\end{array}$ \\
\hline $\mathrm{G}_{3}$ & $\begin{array}{l}1.55^{\mathrm{a}} \pm 0.06 \\
(039)\end{array}$ & $\begin{array}{l}6.42^{a} \pm 0.26 \\
(039)\end{array}$ & $\begin{array}{l}9.32^{\mathrm{a}} \pm 0.37 \\
(039)\end{array}$ & $\begin{array}{l}10.36^{a} \pm 0.35 \\
(024)\end{array}$ & $\begin{array}{l}12.82^{\mathrm{a}} \pm 0.34 \\
(039)\end{array}$ & $\begin{array}{l}16.88^{a} \pm 0.35 \\
(039)\end{array}$ \\
\hline BS & $* * *$ & $* * *$ & $* * *$ & $* *$ & $* * *$ & $* * *$ \\
\hline $\mathrm{BS}_{1}$ & $\begin{array}{l}1.56^{a} \pm 0.04 \\
(204)\end{array}$ & $\begin{array}{l}5.91^{\mathrm{a}} \pm 0.09 \\
(203)\end{array}$ & $\begin{array}{l}9.80^{a} \pm 0.17 \\
(203)\end{array}$ & $\begin{array}{l}10.36^{a} \pm 0.17 \\
(158)\end{array}$ & $\begin{array}{l}13.64^{\mathrm{a}} \pm 0.16 \\
(203)\end{array}$ & $\begin{array}{l}17.17^{a} \pm 0.16 \\
(203)\end{array}$ \\
\hline $\mathrm{BS}_{2}$ & $\begin{array}{l}1.36^{\mathrm{b}} \pm 0.03 \\
(184)\end{array}$ & $\begin{array}{l}4.78^{b} \pm 0.11 \\
(180)\end{array}$ & $\begin{array}{l}8.47^{b} \pm 0.21 \\
(180)\end{array}$ & $\begin{array}{l}09.98^{b} \pm 0.16 \\
(160)\end{array}$ & $\begin{array}{l}11.67^{b} \pm 0.19 \\
(180)\end{array}$ & $\begin{array}{l}15.00^{\mathrm{b}} \pm 0.19 \\
(180)\end{array}$ \\
\hline $\mathrm{BS}_{3}$ & $\begin{array}{l}1.33^{c} \pm 0.06 \\
(078)\end{array}$ & $\begin{array}{l}3.76^{c} \pm 0.11 \\
(068)\end{array}$ & $\begin{array}{l}7.17^{c} \pm 0.36 \\
(068)\end{array}$ & $\begin{array}{l}09.28^{\mathrm{c}} \pm 0.33 \\
(051)\end{array}$ & $\begin{array}{l}9.95^{c} \pm 0.33 \\
(068)\end{array}$ & $\begin{array}{l}13.41^{c} \pm 0.34 \\
(068)\end{array}$ \\
\hline Flock & NS & NS & NS & NS & NS & NS \\
\hline
\end{tabular}


Phenotypic Performance and Response to Selection for Body Weight Traits of Black Bengal Goat (BBG) in a Community Breeding Program

\begin{tabular}{lllllll} 
Gangatia & $1.47^{\mathrm{a}} \pm 0.05$ & $4.84^{\mathrm{b}} \pm 0.13$ & $8.58^{\mathrm{a}} \pm 0.28$ & $09.58^{\mathrm{b}} \pm 0.27$ & $11.86^{\mathrm{a}} \pm 0.26$ & $15.31 \pm 0.27$ \\
& $(154)$ & $(155)$ & $(155)$ & $(130)$ & $(155)$ & $(155)$ \\
Borochala & $1.39^{\mathrm{b}} \pm 0.03$ & $5.03^{\mathrm{b}} \pm 0.13$ & $8.31^{\mathrm{b}} \pm 0.15$ & $09.98^{\mathrm{b}} \pm 0.12$ & $11.87^{\mathrm{a}} \pm 0.13$ & $15.00 \pm 0.14$ \\
& $(143)$ & $(157)$ & $(157)$ & $(117)$ & $(157)$ & $(157)$ \\
Pachpai & $1.38^{\mathrm{b}} \pm 0.05$ & $5.59^{\mathrm{a}} \pm 0.11$ & $8.56^{\mathrm{a}} \pm 0.33$ & $10.07^{\mathrm{a}} \pm 0.29$ & $11.52^{\mathrm{b}} \pm 0.31$ & $15.26 \pm 0.31$ \\
& $(169)$ & $(139)$ & $(139)$ & $(122)$ & $(139)$ & $(139)$ \\
Overall mean & $1.42 \pm 0.03$ & $5.14 \pm 0.07$ & $8.48 \pm 0.17$ & $9.88 \pm 0.16$ & $11.75 \pm 0.16$ & $15.19 \pm 0.16$ \\
& $(466)$ & $(451)$ & $(451)$ & $(369)$ & $(451)$ & $(451)$ \\
\hline
\end{tabular}

BW0, BW3, BW6, BWSM, BW9 and BW12 denote body weights at birth, 3-month, 6-month; sexual maturity, 9-month and 12month; BS denotes breeding strategy; $G_{0}$, foundation flock; $G_{1}$, generation 1; $G_{2}$, generation 2; $G_{3}$, generation 3; Figures in the parenthesis indicate number of observations; ${ }^{*}$, Significant at $5 \%$ level $(p<0.05) ;{ }^{* * *}$, Significant at $0.1 \%$ level $(p<0.001) ;$ means with uncommon superscripts within the same column differed significantly $(p<0.05)$.

The graphical presentation of body weight changes for different ages of male and female kids are illustrated in Fig. 1 and Fig. 2 , respectively. Body weight increased linearly with increasing ages. The figures also show the variations (range) of body weight within population of the same ages. However, variations of body weight within population of same ages increased gradually with advance of ages. The regression equations as shown in Fig. 1 and Fig. 2 indicate that body weight increased at a rate of $1.165 \mathrm{~kg}$ $\left(R^{2}=0.91\right)$ and $1.030 \mathrm{~kg}\left(R^{2}=0.84\right)$ per month for male and female kids, respectively.

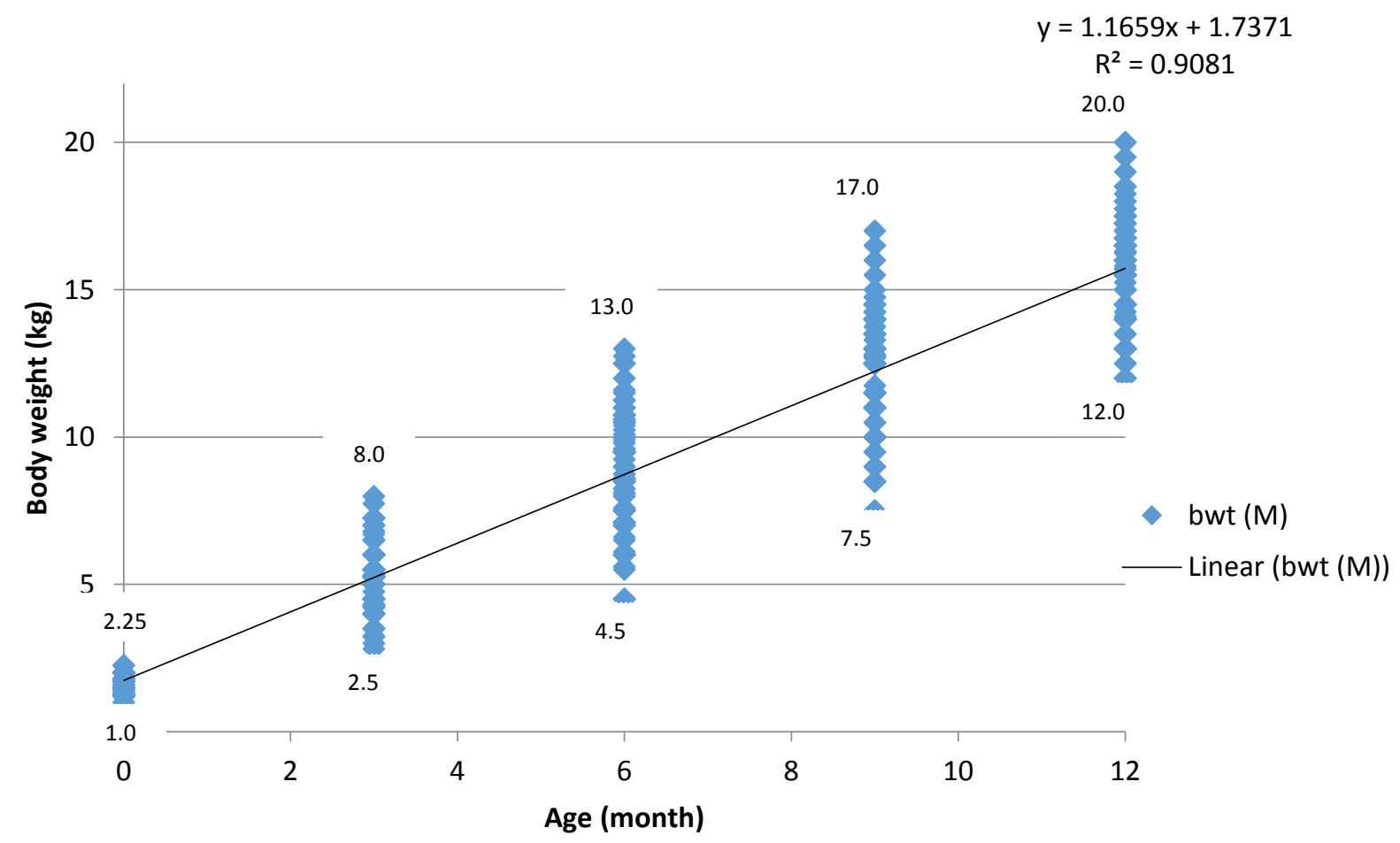

Fig. 1: Growth trend of male kids 
Phenotypic Performance and Response to Selection for Body Weight Traits of Black Bengal Goat (BBG) in a Community Breeding Program

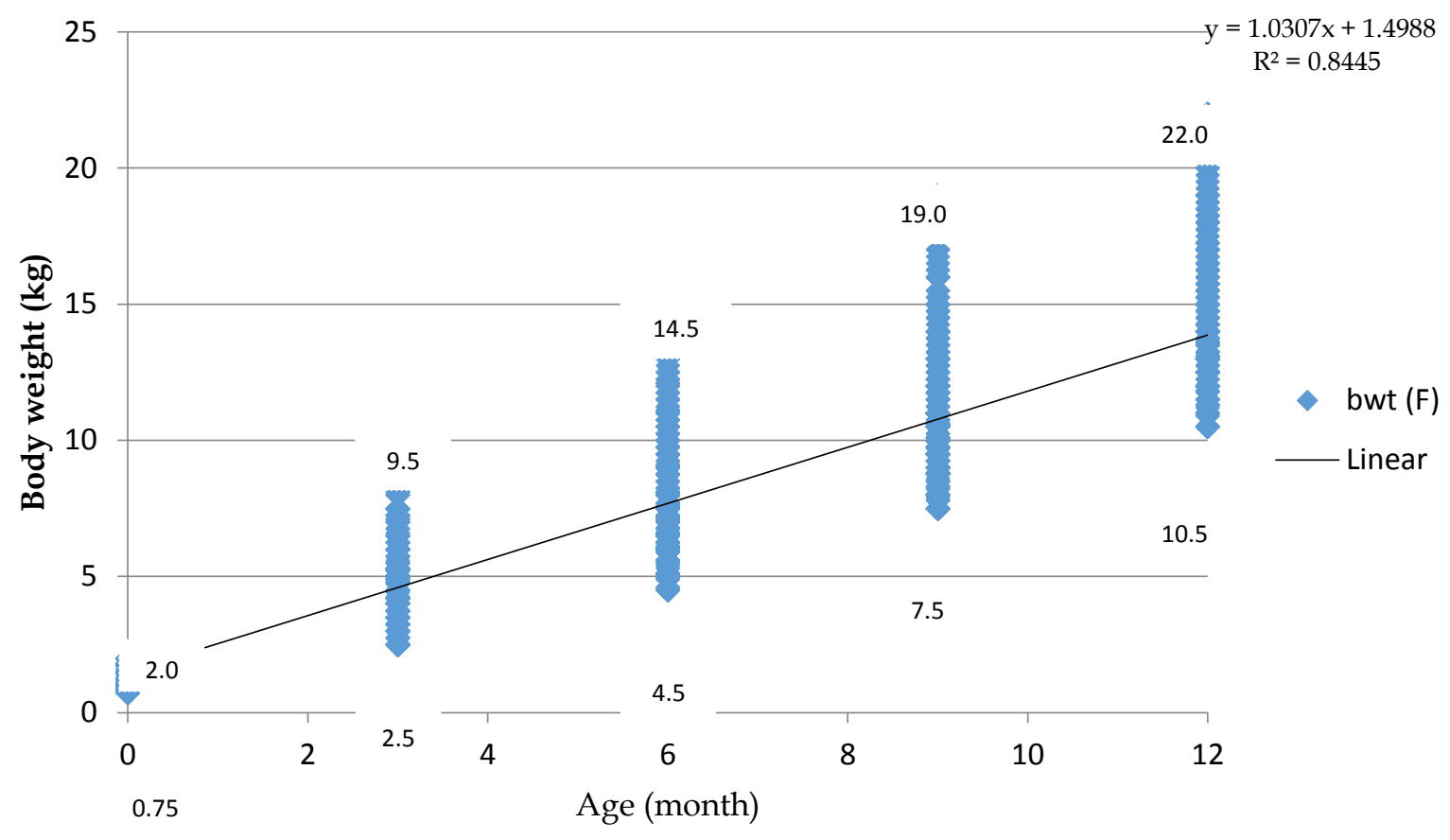

Fig. 2: Growth trend of female kids

\section{Heritability estimates for BW traits}

The variance components and heritability estimates for BW at different ages in BBG are illustrated in Table 2 which shows medium heritability estimates ranged from 0.45 to 0.57 . Amin et al. (2001) in their study reported heritability estimates for birth, 3, 6, 9 and 12 -month of ages to be $0.30 \pm 0.16,0.57 \pm 0.27,0.27 \pm 0.17,0.27 \pm 0.19$ and $0.35 \pm 0.24$, respectively in the same breed. The magnitudes of heritability estimates in their study were medium, except that at 3-month which closely agrees by our estimates. Gupta et al. (2016) also reported medium heritability estimates of Mehsana goat of Gujarat at birth (0.16) and 3-month (0.29), but they obtained higher values for later ages. Mia et al. (2013) also reported medium estimates of heritability (0.45-0.49), while Haque et al. (2012) obtained medium to higher values (0.44-0.66) for those traits in BBG. Faruque et al. (2010) reported higher heritability estimates for birth weight (0.92) and 12-month body weight (0.88), but medium for 3, 6 and 9-month (0.48, 0.34 and 0.45 , respectively). Ray et al. (2016) reported heritability of BW at sexual maturity of indigenous goat in India as $0.34 \pm 0.11$ which is somewhat lower than our study.

Table 2: Variance components and heritability estimates for body BW traits

\begin{tabular}{lllll}
\hline \multirow{2}{*}{ Body weight trait } & \multicolumn{5}{l}{ Covariance component } & \multicolumn{2}{c}{$h^{2}( \pm \mathrm{SE})$} \\
\cline { 2 - 5 } & $\sigma^{2}{ }_{\mathrm{a}}$ & $\sigma^{2}{ }_{\mathrm{e}}$ & $\sigma_{\mathrm{p}}{ }^{2}$ & $0.45 \pm 0.03$ \\
BW0 & 0.034 & 0.005 & 0.076 & $0.54 \pm 0.02$ \\
BW3 & 1.063 & 0.229 & 1.981 & $0.57 \pm 0.02$ \\
BW6 & 2.009 & 0.680 & 3.721 & $0.56 \pm 0.03$ \\
BWSM & 2.048 & 0.143 & 3.636 & $0.49 \pm 0.03$ \\
BW9 & 1.852 & 0.662 & 3.752 & $0.52 \pm 0.02$ \\
BW12 & 1.848 & 0.459 & 3.535 & \\
\hline
\end{tabular}

BW0, BW3, BW6, BWSM, BW9, BW12 denote body weights at birth, 3, 6, sexual maturity, 9 and 12-month age; $\sigma^{2}$ a, additive genetic variance; $\sigma^{2}$, environmental variance; $\sigma^{2}$, total phenotypic variance; $h^{2}$, heritability; $S E$, standard error

The variable degrees of heritability estimates for BW traits in the same genotype as obtained by different authors might be due to effect of environment or maternal influence and also for number of observations. High maternal influence has a tendency to increase the component of environmental variance, thereby lowering heritability estimate. According to Van Vleck and Bradford (1965), the higher estimates of heritability could be attributed to some unknown factors biasing the heritability estimates from sire components upward. The heritability estimates as obtained in the study indicate that mass selection may be more useful for 


\section{Phenotypic Performance and Response to Selection for Body Weight Traits of Black Bengal Goat (BBG) in a Community Breeding Program}

further genetic improvement of BW in BBG. However, early selection may be helpful for taking decision of selection or culling and to reduce feed and management cost of the farmers.

\section{Genetic and phenotypic correlations among BW traits}

The genetic $\left(r_{g}\right)$ and phenotypic correlations $\left(r_{p}\right)$ among BW at birth 3, 6, 9 and 12-month and were estimated and illustrated in Table 3 which indeed shows highly significant $(p<0.01)$ correlations among most pairs of traits. The strengths of correlations are strongly positive, except BWO with others. Actually, there are very little effects of environment on BWO rather than weights at later ages and this could be the reason for lower correlations between BWO with others. In general agreement, positive $r_{g}$ and $r_{p}$ between BW at different ages have been reported by Roy et al. (1997) and Singh (1997), while high and positive $r_{g}$ and $r_{p}$ between BW at different ages in Sirohi goats have been reported by Gowane et al. (2011). Mia et al. (2013) estimated $r_{g}$ and $r_{p}$ of BW among different ages for the same genotype and reported positive correlations ranging medium to high ( $r_{g}: 0.34-0.90$ and $r_{p}: 0.34-0.83$ ) in magnitude which agreed well by our study.

The estimates of $r_{g}$ and $r_{p}$ showed no genetic antagonisms among the BW traits. Mia et al. (2013) and Al-Shorepy et al. (2002) found no antagonism among the BW traits in their studies, which are in consistent with our findings. Table 3 also shows that the correlations among BW at different ages decreased, as the time between measurements increased, except between BW0 with others, which could be explained by an auto correlation that would exist among the genetic and environmental effects associated with the successive measurements (Mia et al., 2013). Mia et al. (2013) also observed the same trends and obtained strong correlations $\left(r_{\mathrm{g}}=0.90\right.$ and $\left.r_{\mathrm{p}}=0.83\right)$ between BW9 and BW12.

Table 3: Genetic correlations (below diagonal) and phenotypic correlations (above diagonal) among BW traits

\begin{tabular}{llllll}
\hline Traits & BW0 & BW3 & BW6 & BW9 & BW12 \\
\hline BW0 & - & $0.173^{* *} \pm 0.046$ & $0.316^{* *} \pm 0.046$ & $0.338^{* *} \pm 0.045$ & $0.384^{* *} \pm 0.045$ \\
BW3 & $0.043 \pm 0.049$ & - & $0.912^{* *} \pm 0.025$ & $0.888^{* *} \pm 0.026$ & $0.864^{* *} \pm 0.028$ \\
BW6 & $0.017 \pm 0.049$ & $0.896 \pm 0.023$ & - & $0.988^{* *} \pm 0.011$ & $0.972^{* *} \pm 0.015$ \\
BW9 & $0.052 \pm 0.049$ & $0.882 \pm 0.025$ & $0.995 \pm 0.010$ & - & $0.984^{* *} \pm 0.012$ \\
BW12 & $0.097 \pm 0.050$ & $0.853 \pm 0.027$ & $0.977 \pm 0.013$ & $0.981 \pm 0.011$ & - \\
\hline
\end{tabular}

BW0, BW3, BW6, BW9, BW12 denote body weights at birth, 3, 6, 9 and 12-month age; **, significant at 1\% (p<0.01)

The direction and degree of strength for $r_{g}$ and $r_{p}$ among BW traits indicate that genes controlling for one of the traits is simultaneously controlling for other traits collaterally. Thus, selection for genetic improvement of one trait will simultaneously improve for other traits as a correlated response. However, selection for BW based on birth weight will have very little chance of improvement for other traits as $r_{g}$ and $r_{p}$ between birth weight with BW at other ages is very low. Selection based on BW at 3month and 6-month may be possible for further genetic improvement of these traits.

\section{Response to selection for BW traits}

The response or genetic progress per generation due to selection for BW traits in BBG are presented in Table 4.

Table 4: Response to selection for body BW traits of BBG in different breeding strategy (BS)

\begin{tabular}{|c|c|c|c|c|c|c|c|c|}
\hline \multirow[t]{3}{*}{ Traits } & \multicolumn{8}{|c|}{ Response $(R)$ to selection measured in kilogram per generation } \\
\hline & \multicolumn{2}{|l|}{$\mathrm{BS}_{1}$} & \multicolumn{2}{|l|}{$\mathrm{BS}_{2}$} & \multicolumn{2}{|l|}{$\mathrm{BS}_{3}$} & \multicolumn{2}{|c|}{ All population } \\
\hline & RPredicted & RActual & RPredicted & $\mathrm{R}_{\text {Actual }}$ & RPredicted & $R_{\text {Actual }}$ & RPredicted & $R_{\text {Actual }}$ \\
\hline BW0 & 0.044 & 0.174 & 0.033 & 0.109 & - & 0.024 & 0.051 & 0.123 \\
\hline BW3 & 0.213 & 0.783 & 0.199 & 0.297 & - & -1.120 & 0.220 & 0.463 \\
\hline BW6 & 0.345 & 0.703 & 0.259 & 0.660 & - & 0.073 & 0.396 & 0.463 \\
\hline BW9 & 0.341 & 0.907 & 0.290 & 0.620 & - & -0.037 & 0.433 & 0.480 \\
\hline BW12 & 0.347 & 0.703 & 0.260 & 0.683 & - & -0.063 & 0.402 & 0.457 \\
\hline
\end{tabular}

BW0, BW3, BW6, BW9, BW12 denote body weights at birth, 3, 6, 9 and 12-month age;

As shown in Table 4 that actual responses were always higher than responses predicted for all BW traits in first two BS. Genetic gains per generation for BW0, BW3, BW6, BW9 and BW12 in all population were predicted to increase by $0.051,0.220,0.396$, 0.433 and $0.402 \mathrm{~kg}$, respectively, while those actually increased by $0.123,0.463,0.463,0.480$ and $0.457 \mathrm{~kg}$, respectively (Fig. 1 to 
Phenotypic Performance and Response to Selection for Body Weight Traits of Black Bengal Goat (BBG) in a Community Breeding Program

Fig. 5). The results also revealed that actual responses for $\mathrm{BW}$ traits in $\mathrm{BS}_{1}$ were higher than actual $\mathrm{BW}$ traits increased in $\mathrm{BS}_{2}$ and $\mathrm{BS}_{3}$. This could be due to superior parents mated in those population. Published literatures on response for BW traits in BBG are very scarce, as community goat breeding approach conducted earlier is seldom. However, Amin et al. (2001) studied direct selection response for BW at different ages in BBG for two progressive generations. They reported an average response per generation to be $0.09 \mathrm{~kg}$ for BW0, which is less than our study. On the other hand, their published report on selection response for BW3 (0.520 kg per generation) closely agrees with our estimate. Interestingly, they obtained selection response for BW6, BW9 and BW12 as to be $0.730,1.05$ and $1.69 \mathrm{~kg}$, respectively which were higher as compared to our findings. The variations of magnitudes for response to selection between works could be due to many factors like selection intensity, genetic or maternal effect, environment, sample size, methods of estimation etc.

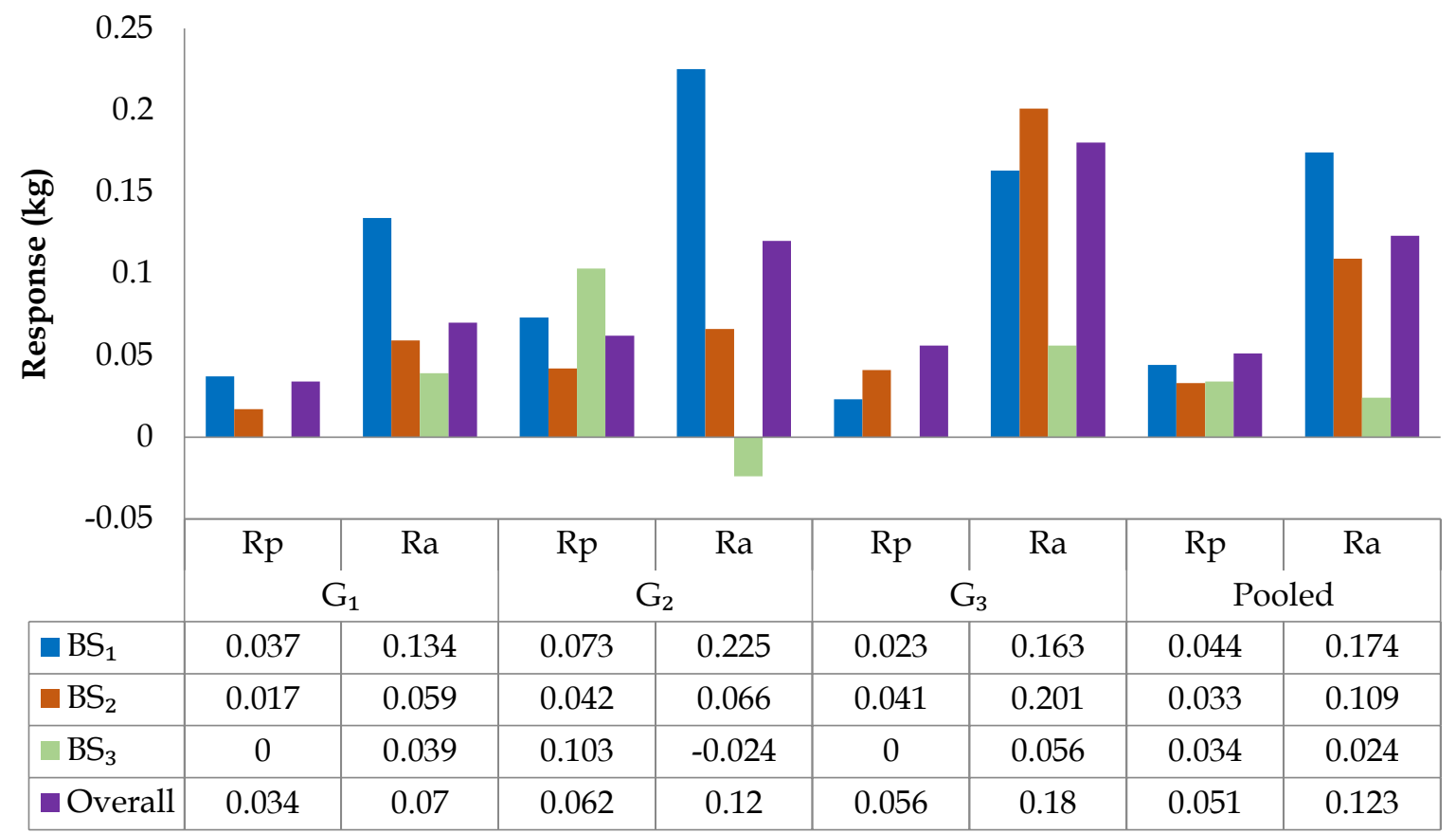

Fig. 1: Response to selection for birth weight $\left(B S_{1}\right.$, breeding strategy $1 ; B S_{2}$, breeding strategy 2; $B S_{3}$, breeding strategy 3 ; $R_{p}$, predicted response; $R_{a}$, actual response; $G_{1}$, generation $1 ; G_{2}$, generation 2; $G_{3}$, generation 3 )

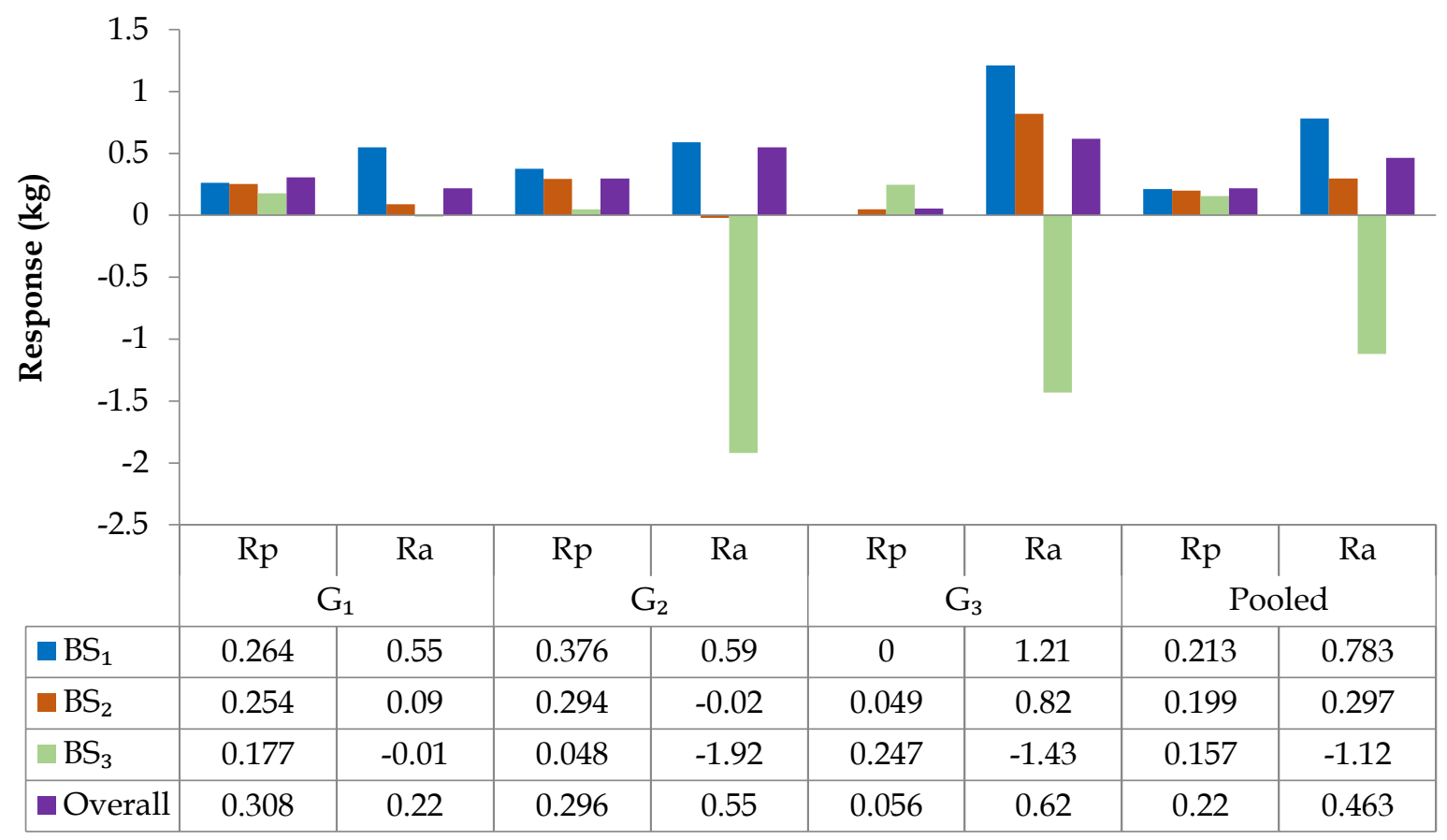

Fig. 2: Response to selection for 3-month body weight $\left(B S_{1}\right.$, breeding strategy $1 ; B S_{2}$, breeding strategy 2; $B S_{3}$, breeding strategy 3; $R_{p}$, predicted response; $R_{a}$, actual response; $G_{1}$, generation 1; $G_{2}$, generation 2; $G_{3}$, generation 3 ) 
Phenotypic Performance and Response to Selection for Body Weight Traits of Black Bengal Goat (BBG) in a Community Breeding Program

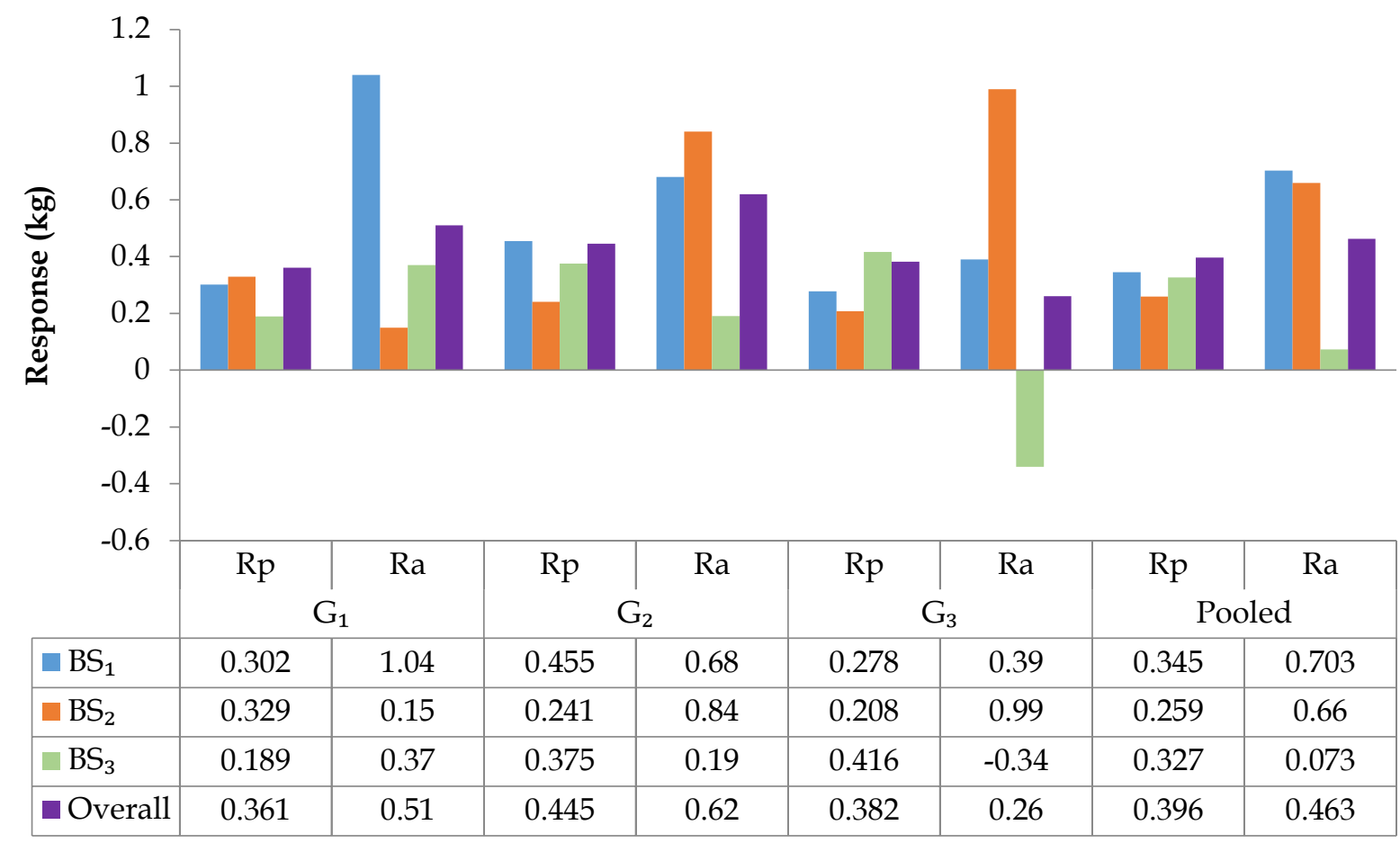

Fig. 3: Response to selection for 6-month body weight ( $B S_{1}$, breeding strategy 1; $B S_{2}$, breeding strategy 2; $B S_{3}$, breeding strategy 3; $R_{p}$, predicted response; $R_{a}$, actual response; $G_{1}$, generation 1; $G_{2}$, generation 2; $G_{3}$, generation 3 )

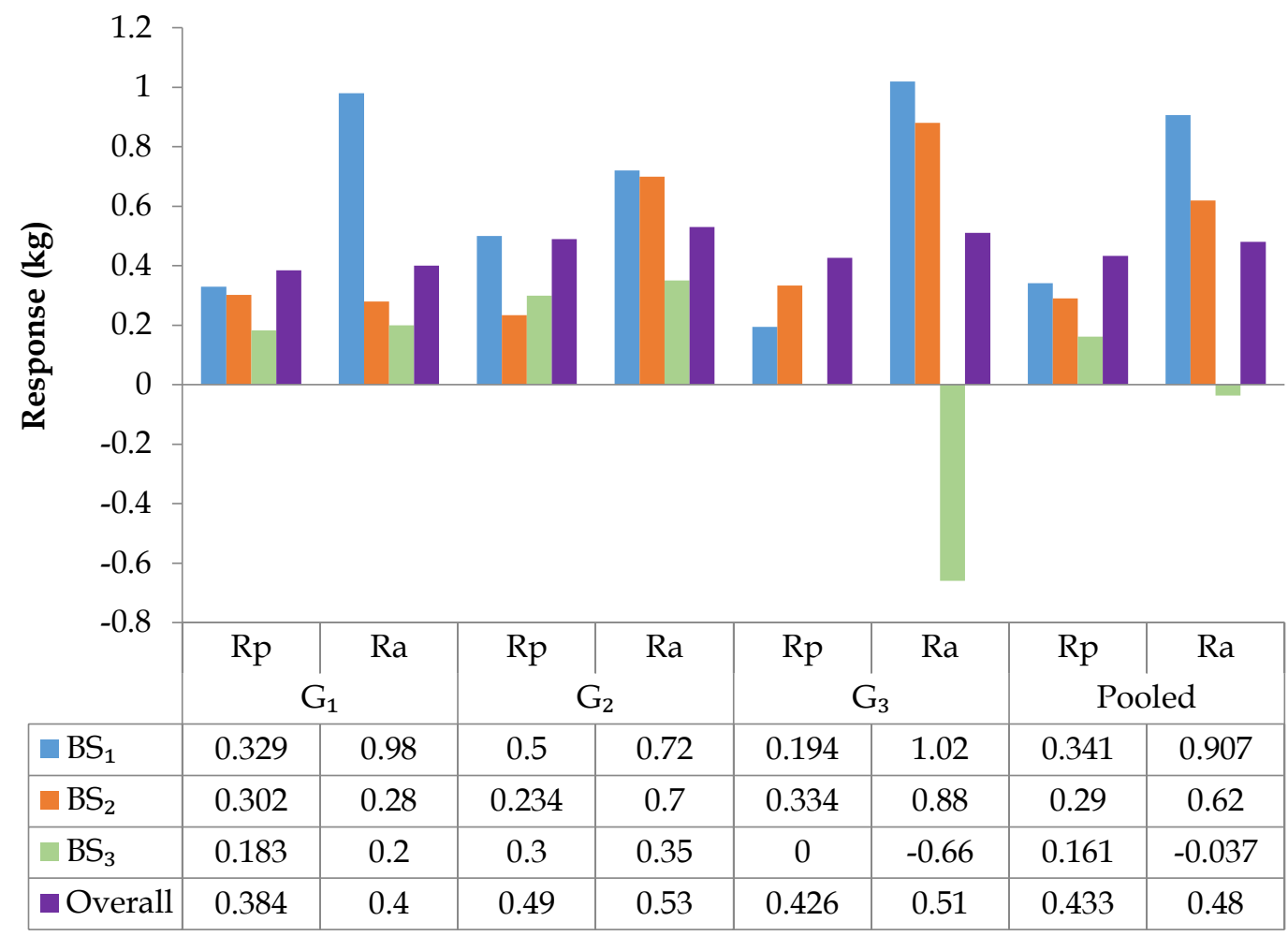

Fig. 4: Response to selection for 9-month body weight $\left(B S_{1}\right.$, breeding strategy $1 ; B S_{2}$, breeding strategy $2 ; B S_{3}$, breeding strategy 3; $R_{p}$, predicted response; $R_{a}$, actual response; $G_{1}$, generation 1; $G_{2}$, generation 2; $G_{3}$, generation 3 ) 


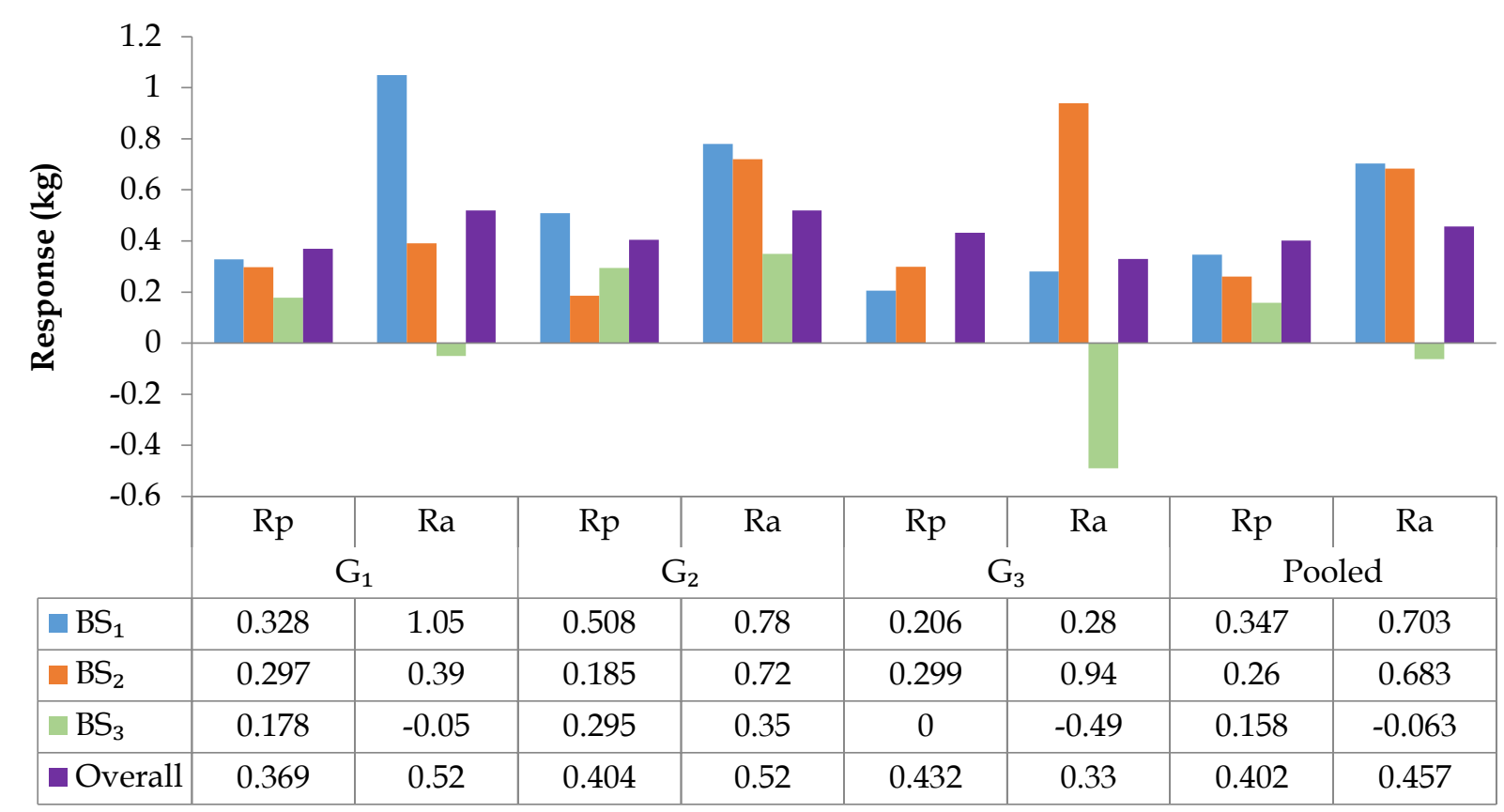

Fig. 5: Response to selection for 9-month body weight $\left(B S_{1}\right.$, breeding strategy 1; $B S_{2}$, breeding strategy 2; $B S_{3}$, breeding strategy 3; $R_{p}$, predicted response; $R_{a}$, actual response; $G_{1}$, generation 1; $G_{2}$, generation 2; $G_{3}$, generation 3 )

\section{CONCLUSION}

Community based breeding program with superior bucks and does, even only superior bucks enhanced BW in progressive generations. The estimates of heritability and genetic correlations for BW traits imply that genetic improvement for those traits are possible collaterally by selection of animals based on individual's own performance. However, genetic improvement of BW is also possible due to moderate estimates of heritability, but selection of animals solely based on birth weight may not result in simultaneous improvement of other BW traits.

\section{ACKNOWLEDGEMENTS}

Due to funding by "UNEP-GEF-ILRI FAnGR Asia Project" for the community goat breeding program in the study areas the authors would like to acknowledge them. The authors are also very much grateful to the community goat owners from where data were collected.

\section{REFERENCES}

1) Acharya RM, Battacharyya NK 1992: Status of small Ruminant production : FAO round table on International Cooperation or small Ruminant Research and Development In $5^{\text {th }}$ Int. Conference or Goats. New Delhi, India, pp. 7- 43.

2) Akhter S, Husain SS, Chowdhur SA, Manzur M, Dev GK 2006: Estimation of variance components and prediction of breeding value for some economically important Traits of Black Bengal goats. Bangladesh Journal of Animal Science 35(12) 20-26.

3) Alam MK 2006: Characterization and performance evaluation of white goat in some selected areas of Bangladesh. M. S. Thesis, Department of Animal Breeding and Genetics. Bangladesh Agricultural University. Mymensingh. pp. 35-69.

4) Al-Shorepy SA, Alhadranu GA, Abdul Wahab K 2002: Genetic and Phenotypic parameters for early growth traits in Emirati goat. Small Ruminant Research 45: 217- 223.

5) Amin MR 2006: Black Bengal- a promising goat genetic resource of Bangladesh. Paper presented at IAEA training program and International meeting entitled "Selective Breeding gene technologies" held in KAERL, Daejeon, Korea. 3-7 Apr, 2006.

6) Amin MR 2014: BLACK BENGAL - a promising goat genetic resource of Bangladesh, Joint FAO and IEA Program, International Atomic Energy Agency (2013-2014), P.O. Box 100, Wagramer Strasse 5, A-1400 Vienna, Austria.

7) Amin MR, Husain SS, Islam ABMM 2001: Reproductive pecularities and litter weight in different genetic groups of Black Bengal does. Asian Australasian Journal of Animal Science 14(3): 297-301.

8) BBS 2010: Censuses of Agriculture 2008. Bangladesh Bureau of Statistics, Dhaka. 
Phenotypic Performance and Response to Selection for Body Weight Traits of Black Bengal Goat (BBG) in a Community Breeding Program

9) Falconer DS 1989: Introduction to Quantitative Genetics. 3rd edition. Longman Group Ltd. England.

10) Faruque S, Chowduury SA, Siddiquee NU, Afroz MA 2010: Performance and genetic prarameters of economically important traits of Black Bengal goat. J. Bang. Agril. Univ. 8(1): 67-78.

11) Gowane GR, Chopra A, Prakash D, Arora AL 2011: Estimates of (co)variance components and genetic parameters for growth traits in Sirohi goat. Trop. Anim. Health Prod. 43: 189-198.

12) Groeneveld E 1998: PEST User's Manual, Institute of Animal Science, Höltystraÿe 10, D-31535 Neustadt, Germany.

13) Gupta JP, Pandey DP, Shah RR 2016: Genetic studies on growth traits of Mehsana goat of Gujarat, India. Indian J. Anim. Res. 50(2): 164-167.

14) Haque GA, Hossain MM, Bhuiyan AKFH, Amin MR 2012: Productive performance and genetic status of Black Bengal goat produced at farmer level through contract breeding program. Bangladesh Journal of Animal Science 34 1-9.

15) Haque MN 2014: Selection of Black Bengal breeding buck through progeny testing. PhD dissertation, Department of Animal Breeding and Genetics, Bangladesh Agricultural University, Mymensingh. Pp. 1-142.

16) Husain SS 1993: A study on the productive performance and genetic potentials of Black Bengal goats. A Ph.D. Thesis, Bangladesh Agricultural University, Mymensingh, pp. 3-108.

17) Husain SS 1999: Sustainable genetic improvement of economic trait of Black Bengal goats through selective and cross breeding. Bangladesh, Agric. Univ. Res. Prog. 10: 72-80.

18) Iniguez L 2004: Goats in resource. Poor systems in the dry environment of West Asia, Central Asia and the Inter- Andcan valleys. Small Ruminant Research 51: 137-144.

19) Islam AFMF 2014: Study on breeding and performance profile of Black Bengal goats in Mymensingh district. MS thesis, Department of Animal Breeding and Genetics, Bangladesh Agricultural University, Mymensingh. pp. 1-45.

20) Islam MR, Amin MR, Kabir AKMA, Ahmed MU 2009: Comparative study between semiintensive and scavenging production system on the performance of Black Bengal goat. Journal of Bangladesh Agricultural Unversity 7 (1) 79-86.

21) MacHugh DE, DG Bradley 2001: Livestock genetic origins: goats buck the trend. Proc. Nalt. Acad. Sci. USA 98: $5382-5384$.

22) Majumder MKH 2011: Characterization of Black Bengal goat in north western region of Bangladesh. M. S. Thesis. Department of Animal Breeding and Genetics, Bangladesh Agricultural University, Mymensingh.

23) Mia MM 2011: Genetic evaluation of performance of Black Bengal Goat. Ph.D. Thesis, Department of Animal Breeding and Genetics, Bangladesh Agricultural University, Mymensingh.

24) Mia MM, Khandoker MAMY, Husain SS, Faruque MO, Notter DR 2013: Estimation of genetic and phenotypic parameters of some reproductive traits of Black Bengal does. Iranian Journal of Applied Animal Science 3(4) 829-837.

25) Paul S, Khandoker MAMY, Moinuddin MA, Paul RC 2011: Characterization of Black Bengal goat. J. Bangladesh Agril. Univ. 9(1): 61-66.

26) Rahman FMD 2007: Prediction of carcass weight from the body characteristics of black Bengal goat. International Journal of Agriculture and Biology, 3: 431-434.

27) Ray S, Dash SK, Dhal SK, Nayak GD, Parida AK 2016: Genetic studies on reproductive performance of indigenous goats in Northern Odisha. Exploratory Animal and Medical Research 6(2): 192-198.

28) Rokonuzzaman M 2000: A study of heterosis on productivity in crosses between Jamunapari and Black Bengal goats. M. S. thesis, Department of Animal Breeding and Genetics. Bangladesh Agricultural University, Mymensingh.

29) Roy R, Saxena VK, Singh SK, Khan BU 1997: Genetic analysis of body weights at different ages in Jamunapari goats. Ind. J. Anim. Sci. 67: 337-339.

30) Singh DK 1997: Genetic studies on post-weaning body weight of Black Bengal and its half breeds with Jamunapari and Beetal goats. Ind.J. Anim. Sci. 67(11): 1015- 1017.

31) SPSS 1998:Statistical Package for the Social Sciences. SPSS Inc. an IBM Company Headquarters. Chicago, Illinois, USA.

32) Van Vleck LD, Bradford GE 1965: Comparison of heritability estimates from daughter-dam regression and paternal halfsib correlation. J. Dairy Sci. 48: 1372-1375. 